IOS Press

\title{
Erratum
}

\section{Erratum to: Recent advances in the epidemiology of inflammatory breast cancer}

\author{
Paul H. Levine* and Carmela C. Veneroso
}

[Breast Disease, 40(3) 2021, 133-142,

DOI 10.3233/BD-210014

https://content.iospress.com/articles/breast-

disease/bd210014

The affiliations of the authors were printed incorrectly. The correct affiliations are:

Paul H. Levine ${ }^{\mathrm{a}}$, Carmela C. Veneroso ${ }^{\mathrm{b}}$

${ }^{a}$ University of Nebraska Medical Center, Department of Epidemiology, The George Washington University (retired), Omaha, NE, USA

${ }^{\mathrm{b}}$ Washington DC, USA

${ }^{*}$ Corresponding author: Paul H. Levine. E-mail: paulhlevine@earthlink.net. 